
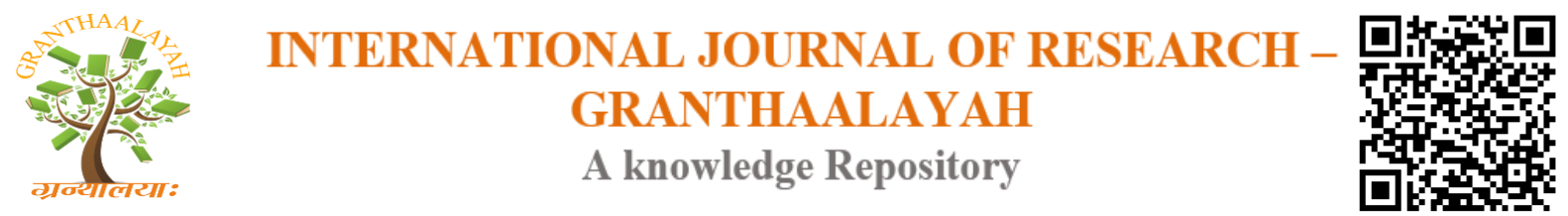

Social

\title{
OCTOBER 16, WORLD FOOD DAY: MAKING INDIA FREE FROM HUNGER
}

\author{
Dr. Amrit Patel ${ }^{* 1}$ \\ ${ }^{* 1}$ Former Deputy General Manager, Agricultural \& Rural Credit Department, International Bank \\ of Baroda, INDIA
}

DOI: https://doi.org/10.29121/granthaalayah.v4.19.2016.2543

\section{ABSTRACT}

Every year some parts of India witness droughts and floods directly impacting on food output. India experienced two drought years [July2014-June15 \& 2015-16] impacting on low food output followed by 2016-17, a year of severe floods. As 36th World Food Day (WFD) will be observed on 16th October, 2016 India can size and capitalize this opportunity to redouble its efforts in creating awareness among all stakeholders by mounting a massive campaign to improve crop productivity per unit area and resources and eliminate hunger, poverty and rural unemployment. India could not achieve Millennium Development Goal-1 to half the percentage of hungry people by 2015. It has now committed to achieve the United Nations Sustainable Development Goal-2 target to "end hunger, achieve food security and improved nutrition, and promote sustainable agriculture" by 2030. In this context, this development perspective article highlights the current Indian scenario and suggests specific aspects to achieve the SDG-Goal 2 and make India free from hunger by 2030.

Keywords:

World Food Day, Hunger, Food Problem.

Cite This Article: Dr. Amrit Patel, "OCTOBER 16, WORLD FOOD DAY: MAKING INDIA FREE FROM HUNGER" International Journal of Research - Granthaalayah, Vol. 4, No. 9 (2016): 113-123.

\section{INTRODUCTION}

\section{WORLD FOOD DAY}

Food and Agriculture Organization [FAO] of the United Nations was established on $16^{\text {th }}$ October 1945 with a mandate "to raise levels of nutrition, improve agricultural productivity, better the lives of rural populations and contribute to the growth of the world economy." The FAO in order to fulfil this mandate has been putting in concerted efforts to achieve food security for all and make sure people have regular access to adequate and better quality food that can help them lead active and healthy lives. Over the period, the FAO has become the reservoir of knowledge about 
food, agriculture and natural resources which it shares among its member countries. Dr. Pal Romany, the former Hungarian Minister of Agriculture \& Food suggested at the $20^{\text {th }}$ session of the FAO conference in November 1979 to observe the World Food Day [WFD] worldwide. Member countries of the FAO endorsed this and proclaimed to observe $16^{\text {th }}$ October each year as WFD to mark the date of establishing the FAO in 1945. The WFD aims at continuously heightening public awareness of the world food problem and strengthen solidarity in the struggle against hunger, malnutrition and poverty. Accordingly, acknowledging that "food is a requisite for human survival and well-being and a fundamental human necessity" the General Assembly on $5^{\text {th }}$ December 1980 endorsed observance of the WFD.

Beginning from 1981 with the theme "Food Comes First" more than 150 countries observe the WFD every year with specific theme that sharply focus the issues responsible for poverty, malnutrition and hunger; identify the areas that need specific actions; and initiate policies, programs and strategic action plans to minimize the incidence. The WFD provides a common focus to help share knowledge and experiences among countries to achieve the expected goals. Most of the themes of WFD highlight areas that need actions focusing adequate and continuous investment in agriculture. The bulk of that investment will have to be sourced from the private sector, with public investment playing a critical role, especially in view of its facilitating and stimulating effect on private investment.

\section{MILLENNIUM DEVELOPMENT GOAL-1}

Achievement of eight Millennium Development Goals [MDG] with a set of measurable timebound targets by 2015 was a pledge by all member-states of the United Nations including India to uphold the principles of human dignity, equality and equity, and free the world from hunger and poverty. Goal-1 of the MDG had target to halve the proportion of poverty and hunger by 2015. However, India could not seize \& capitalize this opportunity to provide social protection net [a viable alternative for stimulating agricultural production] which has the potential to reduce chronic food insecurity by ensuring direct access to food or the means to buy food. Now the United Nations Sustainable Development Goal-2 targets to "end hunger, achieve food security and improved nutrition, and promote sustainable agriculture” by 2030.

India while observing the World Food Day each year should review the outcome and impact of all policies and programs so far introduced, more particularly in previous year and formulate the strategic action plan to make India food secure and achieve" Zero Hunger" by 2030, since it could not achieve the MDG-1 in 2015 to halve the percentage of hungry people of that in 2000. In the context of October $16^{\text {th }} 2016$ being the $36^{\text {th }}$ World Food Day, this article briefly highlights the Indian scenario, constraining factors and suggests specific aspects to make India, Zero Hunger.

\section{SUSTAINABLE DEVELOPMENT GOAL-2}

The member-countries of the United Nations have agreed to achieve 17 Sustainable Development Goals (SDGs) by 2030 of which the SDG-2 reiterates "to end hunger, achieve food security and improved nutrition, and promote sustainable agriculture”. FAO has stated, "Agricultural production must increase by $60 \%$ globally to feed 9.2 billion people by 2050 and 
India by 100\%". This necessitates sustainable, equitable and inclusive solutions in the agricultural sector. Farmers, more importantly small, marginal and women farmers, as producers of food need to be involved, encouraged and incentivized to find specific remedies that address issues affecting food and nutritional security viz. sustainable production, availability, accessibility, affordability and assimilation. In this process, farmers need infrastructure that sustains the productivity, production and profitability of small farms in particular i.e. they need to be facilitated to hassle-free access to scientific knowledge, innovations, production inputs, irrigation, credit, insurance, remunerative markets, among others.

\section{CAUSES, MAGNITUDE AND CONSEQUENCES OF HUNGER}

FAO, World Food Program and International Fund for Agricultural Development define undernourishment, or hunger, in the State of Food Insecurity in the World 2012 report as "food intake that is insufficient to meet dietary energy requirements continuously". According to their report economic recovery, especially in the agriculture sector, will be crucial for sustained hunger reduction. The factors inhibiting agricultural growth include growing biofuel demand, financial speculation in food commodity markets and inefficiencies in food supply and distribution which lead to almost a third of total production being wasted.

Poverty has been often attributed to be the root cause of hunger and malnutrition as poor people do not have sufficient money to buy adequate quantities of healthy food despite food is available. Although food insecurity is primarily a structural problem affecting rural regions, it is exacerbated by natural disasters, political crises and conflicts. At least 40 countries are considered fragile. While stable political stability and good governance are responsible to minimize the incidence of hunger, the percentage share of hungry people as a result of fragility and conflict is increasing.

More than 800 million people worldwide are still chronically hungry. At least a billion more suffer from hidden hunger, malnutrition caused by a diet deficient in vital nutrients. In other words, a little less than two billion people cannot access the quality and amount of food for a healthy and productive life in dignity. Hunger and poor nutrition kill around 8,000 children each day accounting for about $50 \%$ of all child deaths worldwide. Hunger is the greatest risk to health, claiming more lives each year than AIDS, malaria and tuberculosis combined.

Hunger is a major obstacle for human development and the country. It leads to migration and expulsion, conflict and violence, a lack of economic prospects and hopelessness. No other human right is violated as often as the right to food. This violation of human rights and dignity is one of the worst scandals of our modern world. It mainly affects rural areas being home to three quarters of the world's hungry, where there is a lack of employment and incomes leading to abysmal poverty.

Faced with learning difficulties and limited employment opportunities as they grow older, they often face a life of poverty. This scenario demonstrates that the problem is not only serious and acute but also multi-faceted. It is not just a lack of enough food but also the right kind of food accompanied by clean drinking water, better sanitation, knowledge about nutrition in particular. Malnutrition's economic costs to an individual and a country are substantial. Ending child under- 
nutrition could increase a developing country's GDP by $16.5 \%$. Improving nutrition should, therefore, be perceived as an issue of human rights, economics and national growth rather than a welfare issue. When chronic malnutrition cannot generally be reversed, prevention is the only cure.

\section{ZERO HUNGER}

"Zero Hunger" was first proposed at the UN Conference on Sustainable Development in Brazil in June 2012. According to the United Nations' Secretary-General Ban Ki-moon "zero hunger aims for a future where every individual has adequate nutrition".In fact, the FAO in 1974 had declared that by 1984 " no child, woman or man should go to bed hungry and no human being's physical or mental potential should be stunted by malnutrition”. Our former Prime Minister Dr Manmohan Singh had reemphasized in his Independence Day Address that "nobody will be allowed to go hungry". Zero hunger is a challenge that India has necessarily to meet not only for its own people but there cannot be a hunger-free world without India making a significant breakthrough.

\section{INDIAN SCENARIO}

As a signatory to the historic MDGs adopted at the United Nations General Assembly in September 2000, India is committed to end the hunger. However, India is unable to achieve the target to halve the proportion of hungry people by 2015 and was likely to reduce the percentage of underweight children below 3 years of age to $33 \%$ by 2015 as against $26 \%$ [half of what it was in 1990].India has reduced the proportion of hungry people by about $35 \%$ since 1990 but nevertheless India has still 190 million hungry people. India still remains home to one quarter of world's undernourished population, over a third of world's underweight children and nearly a third of world's food-insecure people. Not getting enough food or not getting the right kind of food causes malnutrition. India continues to have one of every three malnourished children in the world. An indicator for chronic malnutrition is stunting, wherein an individual has low height for his/her age. Almost half of the children in India under the age of five are stunted. Deficiencies in essential nutrients are unacceptably high across income levels in India. According to the latest Global Hunger Report, India continues to be among nations where hunger is "alarming". According to the Global Hunger Index [GHI], though country's GHI improved in 23 years from 32.6 in 1990 to 21.3 in 2013, India ranks 63 out of 78 countries having the worst GHI. Most disappointing fact is that India ranks much below some South Asian countries, viz. Sri Lanka (43), Nepal (49), Pakistan (57) and Bangladesh (58). The persisting low level of anthropometric indicators of nutrition in India, for both adults and children even in the midst of intensified interventions for poverty-alleviation, is a cause of serious concern. Intake of dietary energy per person is the most widely accepted indicator of the level of nutrition of the population. The National Sample Survey Organization [NSSO] surveys showed significant declining trend in respect of per capita calorie intake in rural areas from 2153 in 1993-94 to 2020 in 2009-10 and in urban areas from 2091 to 1946 respectively as is evident from the following.

Trend in estimated per capita calorie intake in Rural and Urban India

\begin{tabular}{|l|l|l|l|l|l|}
\hline Period & Rural & Urban & Period & Rural & Urban \\
\hline $1993-94$ & 2153 & 2091 & $2004-05$ & 2047 & 2020 \\
\hline
\end{tabular}




\begin{tabular}{|l|l|l|l|l|l|}
\hline $1999-00$ & 2149 & 2156 & $2009-10$ & 2020 & 1946 \\
\hline
\end{tabular}

NSSO Survey Report, 2012

\section{GOVERNMENT POLICY \& PROGRAMS}

SDG-2 emphasizes food security and promoting sustainable agriculture. The government of India has enacted in 2013 the National Food Security Act to provide subsidized food grain to $75 \%$ the rural and 50\% of urban households for which efforts are made to systematically operationalize its implementation through direct benefit transfer scheme where feasible and making public distribution system [PDS] most effective where necessary. Besides, other measures including food-based social safety nets are being reviewed to make them effective viz. the PDS; the Antodaya Anna Rozgar Yojana, the Mid-day Meal Scheme; the Mahatma Gandhi National Rural Employment Guarantee Scheme. In last two decades, India recorded [i] negative farm growth during five years which were drought years and [ii] $42 \%$ increase in the population as compared to $32 \%$ increase in food output. Between 1994-95 and 2013-14, availability of food grains per capita increased marginally from 471 grams to 511 grams. Following are the constraining factors for dismal agricultural growth.

Low crop productivity: Despite India has the largest irrigated land and ranks second in terms of arable land, the yield of crops is $20 \%-40 \%$ of the world's best levels. Yield of rice in India in 2011 was 3.2 tons per hectare as against 7.5 tons in USA, 6.7 tons in China and 4.3 tons for the world's average. Average yields of coarse cereals were 1.0 ton per hectare in India as compared to 2.7 tons in USA and 2.1 tons in China. The ICAR study showed that the yield gap between the yield of demonstration plots in farmers' fields and the average yield of the area varied by a factor 3 to 6 . Integrating agricultural credit \& crop insurance with technology, production inputs \& markets, farmers can increase wheat production by around $40 \%$ and double paddy production at current levels of technology. Efficient agricultural extension agency and support service providers can help Farmers Bridge the existing gap between the actual crop yields at field level and the potential yields.

Small farmers: Indian agriculture has been characterized as farms of "small and marginal" size. Small and marginal farmers owning less than two hectares constitute $85.9 \%$ of the total and cultivating $44 \%$ of land area, with 0.61 hectare of average size of land holding. Though small farmers are efficient in production their increasing number and shrinking farm size raises questions about their economic viability, sustainability and producing marketable surplus. Disadvantages they face are economies of scale and inadequate access to technology, production inputs, institutional credit, insurance and marketing services. Small farmers are concentrated in rain-fed areas and cultivate crops under a high risk environment, often confronted by frequent droughts, floods and soil erosion.

Drought: Indian sub-continent is predominantly characterized by a tropical monsoon climate and entire region is distinguished mainly by the differences in rainfall in terms of onset, distribution, quantity and withdrawal. While south-west monsoon accounts for $80 \%$ and northeast $20 \%$ of rainfall there is a large variability in the monsoon rainfall on both space and time scales. Only 63 million hectares [45\%] of net cropped area is irrigated. Consequently, some parts of the country experience drought or flood almost every year. In past, country experienced 24 large-scale droughts viz. in 1891,1896, 1899, 1905, 1911, 1915, 1918, 1920, 1941, 1951, 
1965,1966, 1972,1974, 1979, 1982, 1986, 1987,1988, 1999,2000,2002,2009 and 2012.. About 49.8 million hectares [15.2\% of geographical area] is flood-prone and 10 to 12 million hectares are actually flooded each year.

Health of Soil: Intensive agriculture for increasing food production has caused problems of nutrient imbalance, greater mining of soil nutrients to the extent of 10 million tons annually depleting soil fertility, emerging deficiencies of secondary and micronutrients, declining water table level and its quality, decreasing organic carbon content, increasing soil erosion and degradation leading to overall deterioration of soil health. According to ICAR [2010], out of total geographical area of 328.7 million hectare in India about 120.4 million hectares (37\%) are affected by various kinds of land degradation. This includes water and wind erosion (94.9 million hectares), water logging (0.9 million hectares), soil alkalinity [3.7 million hectares], soil acidity (17.9 million hectares), soil salinity (2.7 million hectares) and mining and industrial waste (0.3 million hectares). Frequent droughts, floods and climatic variability/aberrations, also, impact soil fertility and cause land degradation, thereby, affecting/threatening crop production across the country.

Ineffective services: According to "Situation Assessment of Indian Farmers", only about 28\% of all farmers use any kind of agriculture-related information that is available rather than what they need. While about $72 \%$ of farmers do not have any source of information that can help them adopt latest technology, most farmers are unable to access credit, insurance and marketing services from the established institutions. The post-harvest losses exceed $25 \%$ annually. For marketing, small farmers have to deal with multiple layers of middlemen. For example, farmers sell in village itself $85 \%$ of wheat and $75 \%$ of oil seeds in Uttar Pradesh, $70 \%$ of oil seeds and $35 \%$ of cotton in Punjab, and $90 \%$ of jute in West Bengal. These middlemen take away about $47 \%$ of the price of rice, $52 \%$ of groundnut and $60 \%$ of potatoes. On an average, Indian farmers realize only $20 \%$ to $25 \%$ of the value paid by consumers.

\section{NEED FOR FOCUSED ATTENTION}

For "zero hunger", India will have to ensure [i] 100\% access to adequate food all the year round [ii] all food systems are sustainable [iii]100\% increase in smallholder productivity and income [iv]zero loss or waste of food in any form [v] zero stunted children of less than 2 years. To combat the challenge of zero hunger successfully [i] the government should develop state-of-theart technologies and put in place effective mechanism to implement and review/monitor the national food security program [ii] focus should shift from mere access to enough food to enough of the right kind of food [iii] efficient implementation of safety-net programs to prevent disease, provide safe drinking water, adequate sanitation and education [iv] stronger political will needs to be demonstrated right from policy-making to commitment by administrators in a transparent manner for result-oriented implementation to make hunger and malnutrition a reality of the past. For raising $100 \%$ increase in food output to feed India's teeming millions by 2030, it necessitates a modern and professional agricultural sector embodying following components that can boost farm productivity [food crops including pulses, fruits \& vegetables, livestock, fish] and make India "zero hunger" through adequate availability of nutritious food, its affordability, easy and reliable access, proper assimilation and stability of food production. 


\section{RESEARCH}

While the first Green Revolution had its genesis in the Seed-Fertilizer-Irrigation technology, the second Green Revolution should originate from radiation-induced mutation technique and Biotechnology along with integrated nutrient, pest \& water management technology. The International Atomic Energy Agency has called for increased investments in radiation-induced mutation techniques that help in producing crop varieties with high yields and disease resistance, and can grow in stressful conditions such as drought, flood and salinity. This technique has been in use since 1920s and more than 3000 varieties of 170 different plant species have been released for cultivation. Similarly, biotechnology in recent years has created unprecedented opportunities and revolutionized research activities in the area of agriculture viz. plant tissue culture and Genetic engineering leading to transgenic plants carrying desirable traits like insect and herbicide resistance; tolerance to salinity, drought and major pests; enhancing nitrogen fixing ability, improving storage/shelf life, proteins and crops for food processing, thereby addressing problems related to malnutrition, poverty and hunger. India should, therefore, concentrate on inventing new seeds and planting material of various field crops through application of new technology. . Research should focus on food crops, pulses, oilseeds, vegetables, fruits, milk, fish, eggs, broilers and meat so that people can access nutritional and balanced food.

\section{POTENTIAL OF INFORMATION \& COMMUNICATION TECHNOLOGY}

By June, 2014, rural India had about 122.4 million [68.32\%] households with mobiles exhibiting mobile connectivity has become a basic service in rural areas. Rural mobile subscriber base is growing twice as faster compared to urban subscriber base. As of March 2015, the national teledensity was $79 \%$ and rural teledensity 46.5\%. Telecom Policy aims to increase rural teledensity to $60 \%$ by 2017 and $100 \%$ by 2020.Information and Communication Technology (ICT) has the potential to revolutionize Indian agriculture in terms of raising crop productivity and profitability per unit area and resources. Several apps are now available and many more can be developed which can help farmers access authentic, accurate and timely information related to high-yielding variety seeds, production-enhancing and cost-minimizing farming practices, efficient use of water including micro-irrigation system, integrated nutrient and pest management, post-harvest management practices, measures to mitigate adverse impact of climate change and marketing of farm produce in domestic and international markets. In public-privatepartnership mode following farmer-friendly farm portals can be developed and farmers incentivized for their use.

- Technology: Production-enhancing proven crop-specific technologies [from pre-sowing to harvesting and post-harvest management] based on soil \& water analysis. Separate for dry land \& irrigated farming focusing efficient use of seeds, fertilizers, water, pesticides, farm equipment \& labour; and reclamation of degraded, saline $\&$ alkaline land.

- Production inputs \& farm equipment: Crop-specific reasonably priced standard quality production inputs [seeds, fertilizers, pesticides, etc.] and farm equipment and machinery along with sources of availability

- Post-harvest services: Storage, transport, processing and packaging.

- Institutional services: Land records, farm credit, insurance, marketing, weather, farmerproducers' organizations, market yards, procurement centers 
- Irrigation: Strategic actions to resolve following serious issues are necessary in order to ensure that share of food output under irrigated farming increases to $75 \%$ from $56 \%$ by 2016-17.

- Incomplete projects: There has been an increase in the number of incomplete projects awaiting completion since the end of IV Plan. The backlog has remained between 500 and 600 projects since then. The backlog declined at the end of VII Plan but increased again to the present level. Currently, there are 557 irrigation projects yet to be completed. Andhra Pradesh has completed only 17 projects out of the allotted 105 projects, followed by Karnataka [33/305], Maharashtra [94/186] and Madhya Pradesh [90/242] projects.

- Time and Cost overruns: Worst part of the inordinate delay in completion of projects has been the time and cost overruns. A study by the Planning Commission on cost overruns found that for a representative 12 projects, there was an escalation of the order of $138 \%$ over the original cost. There was a very high cost escalation of $1,000 \%$ and more for 24 out of the 151 major projects taken up earlier than 1980 and the average escalation is around $200 \%$ for major projects starting from 1985. In the case of medium projects, there are 24 projects with a cost escalation of $500 \%$ or more.

- Underutilization: The gap between the irrigation potential created [IPC] and the irrigation potential utilized [IPU] is steadily increasing from the First Plan. Currently IPU is 80 million hectares [73.39\%] as against IPC of 109 million hectares.

- Over the years, there has been a manifested lack of attention to water legislation, water conservation, water use efficiency, water harvesting and recycling and infrastructure.

- India has a weak framework for sustainable irrigation management. States can consider policy, regulatory and institutional framework for the efficient, sustainable and equitable allocation of water.

- Most States have yet to enact Act to facilitate participation of stakeholders in Participative Irrigation Management [PIM] program.

- Other key priorities include [i] reorganization, strengthening and capacity building of irrigation and drainage departments that can successfully seek participation of farmers and other agencies in PIM [ii] improving cost delivery [iii] allocating sufficient resources for operations and maintenance, sustainability of investments and arresting rapidly deteriorating existing irrigation infrastructure.

- Micro-irrigation System: The study of nine promising States in 2010 revealed that area covered under Drip and Sprinkler irrigation was 14,28,460 hectares[12,25\%] and $24,42,430$ hectares [7.99\%] as against potential of 1,16,59,000 hectares and 3,05,78,000 hectares respectively. A campaign should be launched to create awareness among farmers about the importance of micro-irrigation system through effective demonstrations to make them believe what they see themselves and learn from other farmers who have successfully adopted and benefited.

\section{FOOD MANAGEMENT}

Farm output in India increased from 208 million tons in 2005-06 to an estimated 265.04 million tons [MT] in 2013-14 but declined significantly to 252.04 MT in 2014-15 and is estimated to be 253.16 MT in 2015.16. The worst part has been that a significant percentage of food produced never reaches the consumers for a plethora of reasons. The former minister of agriculture, Sharad Pawar once said that India is wasting food products worth Rs.50,000 crore each year, i.e. nearly 
$40 \%$ value of total production. These figures of economic costs of wastage do not, however, reflect the quantity of food wasted annually. For example, meat accounting for about $4 \%$ of food wastage accounts for $20 \%$ of the wastage costs whereas fruit and vegetable losses accounting for $70 \%$, account for about $40 \%$ of economic costs. High wastage rates are often responsible for doubling prices of fruits and vegetables and $50 \%$ increase in the cost of milk making them unaffordable to poor. Apart from wastages of perishable food, wheat and rice are also abundantly wasted as annually around estimated 21 MT of wheat rots and is infested by insects and pests because of inadequate /inappropriate storage facilities accompanied by inefficient management practices of the Government-managed Food Corporation of India [FCI] with no accountability The solution to the country's future hunger problem lies in formulating a strategic action plan to minimize losses by $90 \%$ by $2016-17$ of the currently estimated wastage of $33 \%$ to $50 \%$ of all food produced.

The high food prices/ food inflation in the country can partly be attributed to these high wastage rates. High food inflation impacts considerably the poor since food accounts for $31 \%$ of their average monthly household expenditure. Major factors responsible for wastage of perishable food include, inter alia, viz. absence of modern supply chains that can efficiently link the food grown by farmers to consumers, lack of adequate financial investments in cold storages and refrigerated vans, erratic electricity supply, poor road connectivity and lack of investmentfriendly policies that discourage the private sector to invest in creating this infrastructure. According to the IIM, Kolkata, country has estimated cold storage facilities for only about $10 \%$ perishable food products and the pressing need is for another 370 MT of cold storage facilities for perishable products. Gross mismanagement of the FCI to store wheat and rice has rendered FCI itself a part of the problem rather than a solution. Even the former Food Minister K V Thomas had once described FCI as a "white elephant that needs to be revamped from top to bottom." This transformation, however, never happened. Mr Thomas, also, led a delegation to China to study the China's impressive system of food production, procurement, storage and handling food-grains which could have been evaluated, modified and emulated to suit to our situation. Even, this should be done now. Now, the recommendations of the Shantakumar Committee on FCI[2014-15] on restructuring, among others, should be forthwith discussed, debated and implemented. The Government spends nearly 1\% of its GDP for its totally mismanaged public food distribution system. While cost of food production, procurement, transport, storage and distribution has significantly increased, inefficient food management system has resulted into huge wastage, pilferages and deterioration in food quality, not even acceptable as cattle-feed. The Independent Evaluation Office reveals that Government spends Rs.3.65 to deliver Re 1 of food while 57\% of subsidized food-grains do not reach the intended beneficiaries and close to $36 \%$ of food-grains are siphoned off in the supply chain. According to one expert grains trade analyst, grains procured @ Rs. $13.50 / \mathrm{Kg}$ ultimately costs Rs.39.50/Kg since additional costs are incurred towards [i] procurement incidentals, viz. local taxes, bagging, transport to local warehouse [ii] storage costs viz. interest, warehousing and transport cost for distribution.[iii] central government/ FCI paying mandi taxes or market charges to major States viz. Punjab, Haryana, Andhra Pradesh and Madhya Pradesh [iv] significant costs during distribution under the PDS [from warehousing to fair price shops to households].[v] establishment costs of FCI [vi] each State having its own administrative infrastructure and fair price shops seeking additional commission as retailing expenses. Thus, subsidy amount just doubles@192\%. 
It is, therefore, necessary to develop effective food production, procurement, storage and management system, methods and procedure through policy intervention and programs that can [i] produce food grains as expected/targeted annually even under frequent unpredictable weather conditions, drought and floods in some parts of the country[ii] formulate a strategic action plan to minimize food wastages/ losses by $90 \%$ by 2016-17 [iii] facilitate the estimated level of only need-based procurement preferably in strategic districts in each State with complete safe storage system [iv] create additional facilities for quick and cost-efficient transport, processing and storage and $[\mathrm{v}]$ redesign the public distribution system and transparent grievance redress mechanism.

\section{FOOD SAFETY STANDARDS}

Food safety and its quality are integral part of nutritional security.Adulterated food is a risk to human health. Food, also, serves as a medium of growth for harmful bacteria and fungus that can cause food poisoning. Foodborne illnesses contribute significant cost for health care. Despite the existence of the Food Safety Standards Authority of India since 2011, India's food chain continues to suffer from excessive toxicity, brought on by the rampant and unrestrained use of pesticides. Official data released some time ago showed nearly $18.7 \%$ of samples tested [samples of commonly consumed foods like vegetables, fruits, milk, pulses, meat and spices] contained pesticide residues in varying degrees. In over $2.6 \%$ of the samples, the toxicity level was higher than the permissible limits. The incidence of toxicity seems to have nearly doubled when compared to similar studies in the past. Nor is the problem confined to big cities, although Delhi and Mumbai are among the worst hit: samples from small urban centers too have failed to pass the safety test. In case of milk, 1,226 [68.4\%] samples of milk were non-confirming to the Food Safety standards[FSS] which were significantly more than double [565; 31.6\%] that confirmed to the FSS. The non-conforming 845 samples in urban areas accounted for $68.9 \%$ as against $381(31.1 \%)$ in rural areas. In urban areas, packet and loose samples were 282[33.4\%] and $563[66.6 \%$ ] respectively as compared with 64 (16.8\%) packet samples and $317(83.2 \%)$ loose samples in rural areas. The study indicated [i] addition of water to milk is most common adulterant which reduces the nutritional value of milk [ii] presence of detergent in some cases was noticed. Both these are a serious health risk to the consumers.

Investment: To accelerate the agricultural growth rate, which has significant influence on country's GDP and reduction in hunger and poverty, significant amount of capital formation in agriculture supported by public and private sectors is a sine qua non in specific areas viz. [i] development of irrigation [exploiting potential surface irrigation and groundwater resources, making available electricity/power to extract groundwater] [ii] soil and moisture conservation and land improvement [iii] improving drainage system [iv] strengthening flood control measures [v] all weather roads connecting all villages and towns to facilitate easy and timely transport [vi] storage, warehousing, preservation and processing facilities[vii] value chains system and integrated marketing infrastructure [viii]developing sound information, communication and market intelligence system [ix] building integrated agricultural research, extension and education system [x] soil and water testing facilities [xi] production, quality control and pricing system to facilitate competitively and timely availability of farm inputs [seeds, fertilizers, pesticides, fuel, farm equipment and machinery etc.][xii] Establishing the state-of-the-art agricultural meteorology in each agro-ecological region. 


\section{REFERENCES}

[1] Anonymous [2014], Annual Report, Reserve Bank of India, Mumbai

[2] Anonymous [2014], Annual Report, National Bank for Agriculture \& Rural Development, Mumbai

[3] Government of India [2012], Twelfth Five Year Plan 2012-17, Planning Commission, New Delhi

[4] Government of India [2013a], Agricultural Statistics at a Glance, Department of Agriculture \& Cooperation, Ministry of Agriculture, New Delhi

[5] Government of India [2014] Annual Report, Department of Agriculture \& Cooperation, New Delhi

[6] Kalkoti G. et al, Bank Credit to Agriculture in India: Policy, Performance and Issues Manan Prakshan, Mubai, 400057

[7] Joshi, P.K [2015], Has Indian Agriculture Become Crowded and Risky? Status, Implications and Way Forward: Indian Society of Agricultural Economics, Mumbai 400 063 